CESIS Electronic Working Paper Series

Paper No. 264

\title{
Human Capital in Cities and Suburbs
}

\author{
Kevin Stolarick \\ Charlotta Mellander \\ Richard Florida
}

January 2012 


\title{
Human Capital in Cities and Suburbs
}

\author{
Kevin Stolarick, Charlotta Mellander*, and Richard Florida
}

\begin{abstract}
Stolarick is Research Director of the Martin Prosperity Institute in the Rotman School of Management, University of Toronto, kevin.stolarick@rotman.utoronto.ca.

Mellander is Research Director of the Prosperity Institute of Scandinavia, Jönköping International Business School, charlotta.mellander@ihh.hj.se.

Florida is Director of the Martin Prosperity Institute in the Rotman School of Management, University of Toronto, florida@rotman.utoronto.ca.
\end{abstract}

${ }^{*}$ Corresponding author

\begin{abstract}
Research on human capital generally focuses on the regional level, and neglects the relative effects of its distribution between center cities and surrounding suburbs. This research examines the effects of this intra-metropolitan distribution on economic performance. The findings indicate that this distribution matters significantly to US regional performance. Suburban human capital matters more than center city human capital. However, this varies by regional size. Suburban human capital has the biggest effect on regional economic performance in smaller and medium size metros. Center city human capital has a relatively larger effect on economic performance in regions with over one million people.
\end{abstract}

JEL: O3 R1 R2 J24

Key words: Human Capital, Density, Intra-metropolitan distribution, Income, Housing prices 


\section{Introduction}

In his classic work on The Wealth of Nations (1776) Adam Smith long ago identified the "acquired and useful abilities of all the inhabitants or members of the society" as something akin to a "fourth factor of production" (e.g. Samuelson and Nordhaus, 2004) operating alongside land, labor and production, noting that: "The greatest improvement in the productive powers of labour, and the greater part of the skill, dexterity, and judgment with which it is anywhere directed, or applied, seem to have been the effects of the division of labour"'(Smith, 1776; book 1, page 7). Jane Jacobs (1969) later argued that the clustering of talented and energetic people in cities is the fundamental driving force of innovation and economic development, more important even than the efficiency gains associated with the deepening division of labor within firms. Lucas (1988) formalized Jacobs' insights advancing the construct of "external human capital" or "Jane Jacobs' externalities" as playing a fundamental role in the "mechanics of economic development. Cross-national studies (Barro, 1991; 1997) have documented the role of human capital in national economic development, while urban economics and regional research (Florida, 2002; Berry and Glaeser, 2005; Florida et al. 2008) has found that human capital also plays a key role in the growth and development of metropolitan regions.

Virtually all studies of the association between human capital and urban and regional development focus on the relationship between the two at the regional or metropolitan level. Human capital is measured broadly across metropolitan regions 
on the whole. But following the ideas of Jacobs (1969) and Lucas (1988) on the role of human capital concentration, density and externalities in economic growth and development, it is likely that it is not just the overall level of human capital that matters but its distribution within regions as well.

Metropolitan regions which combine central cities and their surrounding suburbs vary widely: They come in a wide variety of shapes and sizes. Some have concentrated central cities or cores - for example within the greater New York metropolitan area, Manhattan has heavy concentrations of business and also significant concentrations of higher income, higher skill higher human capital individuals. Other regions are more sprawling, take Los Angeles for example, with higher-income, higher skill, higher human capital individuals residing mainly in the suburbs.

This is the core issue our research takes up. We focus on the effects of the distribution of human capital within regions- specifically between cities and suburbs - on regional economic performance. To get at this, we empirically examine the effects of the distribution of human capital across core cities and suburbs for 331 US metropolitan regions. We utilize two measures of human capital: the distribution of human capital per population or per capita measured as the percentage of adults with a bachelors' degree or greater, and the density of human capital, that is the number of adults with bachelors' degree or greater per square kilometer. We examine the effects of the distribution of human capital between cities and suburbs 
on both measures on two key measures of regional economic performance: average metropolitan income and median metropolitan housing prices, while controlling for other factors. We run a series of regression models to capture relative explanatory power between of average human capital level across metros and the distribution of human capital between city centers and suburbs. We examine the effect of the overall human capital level, city and suburban human capital, and other key control variables on our two key measures of regional economic performance. We run the regressions for all metro regions, and also separate into major regional size categories.

The key findings indicate that the distribution of human capital within metros - that is between cities and their surrounding suburbs - matters significantly to regional economic performance. Our variables which measure the distribution of human capital shares for center cities and suburbs explain more of the variation in regional income than the variable for metropolitan human capital overall. Human capital density matters relatively less overall, but increases for smaller regions. The intra-regional distribution of human capital density also adds more to the explanatory power in the housing value regressions. Generally speaking, our findings indicate that suburban human capital matters more than center city human capital. But this varies by regional size. Suburban human capital has the biggest effect on regional economic performance in smaller and medium size metros. But, 
city human capital has a relatively larger effect on economic performance in the largest metropolitan regions, those with over one million people.

\section{Theory and Concepts}

The literature on human capital and regional economic performance is considerable. Ullman (1958) was among the first to highlight the role of human capital on regional development. Jacobs (1969) argued that cities are formed by geographic concentration of diverse activities and highly skilled people. She also drew attention to the distinctiveness of cities vis-à-vis industrial firms. She argued that while firms specialize and divide labor into more specified and productive uses, cities organize natural, industrial and human inputs to facilitate innovation and production. Therefore in Jacobs' view, cities become the key arena for the clustering combination and recombination of skilled individuals that give rise to new innovations which create new work and spur economic development. Lucas (1988) later refined Jacobs' contributions regarding cities and the collocation of skilled people, casting them in terms of the locational advantages that stem from "human capital externalities" - essentially the ancillary benefits that come from the collocation of talented, ambitious and entrepreneurial people. He formalized the role of dense urban areas which localize human capital and information, create knowledge spillovers, and become engines of economic growth. Cities reduce the 
cost of knowledge transfer, so ideas move more quickly, in turn giving rise to new knowledge more quickly.

A wide range of empirical studies have documented the role of human capital in national and regional growth. Barro (1991), Rauch (1993), Simon and Nardinelli (1996) and Simon (1998) all confirm the relation between human capital and growth on a national level. Glaeser (2000) provides empirical evidence on the correlation between human capital and regional economic growth. Firms locate in areas of high human capital concentration to gain competitive advantages, rather than letting suppliers' and customers' geography alone dictate their location. Glaeser and Saiz (2003) find that skilled cities grow, relative to less skilled cities, through increases in productivity.

Other studies find that human capital is becoming more concentrated. Berry and Glaeser (2005) document the growing divergence of human capital levels across cities, finding that the distribution of human capital has gone from relatively even among US metropolitan areas to increasingly divergent.. There are reasons to believe that such divergence will continue (Shapiro 2005).

Research also finds that human capital is not only associated with higher regional incomes but higher housing values (Shapiro, 2005; Gyourko et al., 2006). Part of this is via an income effect, where higher incomes create higher demand for housing. This is obvious both in the Manhattan effect which takes place in dense 
urban cores and in a Greenwich effect which occurs in upscale suburbs. But research has found that other factors also play a role.

Higher income, higher human capital households also exhibit a preference for amenity (Florida, 2002 a, b, c). Glaeser et al. (2001) indentified an urban amenity premium that works alongside an urban productivity premium to effect housing prices. Gyourko et al. (2006) identified a small number of super star cities which support housing prices far above average, over what their productivity premium might suggest. Florida and Mellander (2010) find additional evidence for this amenity effect, finding that factors which proxy for regional amenity (like the presence of large concentration of artists and cultural creatives) have a significant effect on housing values.

However, virtually all of these studies operate at the metropolitan level. There has been little research which empirically examines the effects of the intrametropolitan distribution of human capital across cities and suburb on regional economic performance - measured as metropolitan average income and median housing values.

There are good reasons however to believe that it does. One strand of urban economics per Jacobs (1969) and Lucas (1988) would suggest that dense concentrations of human capital might gain advantages in productivity and innovation, thus leading to higher levels of economic performance. These denser core 
areas might also be thought to gain advantages in the provision of the sorts of amenities that have been found to attract highly-skilled, high human capital individuals and households (Glaeser et al, 2001; Florida, 2002). On the other hand, many leading high-tech metros like Silicon Valley, the North Carolina Research Triangle, and even greater Austin are more suburban in nature, defined by industrial or tech parks and suburban style housing - Kotkin (2000) dubbed them "nerdistans," citing a suburban-preference among engineers and high-tech professionals. And, many upscale suburbs are composed almost exclusively of high-skilled, high-income, high human capital individuals and households, as noted above.

Urban economics gives us a rationale to understand this. Tiebout's classic formulation (1956) shows how individuals and households select specific locations based on their income and preferred bundles of service and amenities. Muth (1961) provides the basic framework to understand the tradeoff between income and housing costs and how it relates to city growth. Cities that increase in income and/or population can be expected to spread out in geography. Cities with traffic congestion or high commuting costs will decrease the incentives to move out from the center.

A recent study by Lee (2010) investigates the sorting of human capital between urban and rural areas. Although the typical expectation is that urban workers will receive a wage premium from agglomeration effects and as compensation for higher living costs, Lee finds that in some cases there is actually a wage premium discount for some urban workers. This is attributed to the greater availability and variety of consumption opportunities available in urban areas. Some 
workers find increased utility from access to consumption opportunities and don't require additional wages. In this case, high skill workers can be less expensive than lower skill workers and employed with greater frequency. The findings of Lee's empirical analysis of the medical profession support this line of thinking. Hospitals in urban centers have a higher ratio of doctors to nurses, the doctors are paid less, and the nurses are paid more than their counterparts in rural areas. Urban doctors are more likely to be specialists and graduates of more highly ranked medical schools than rural doctors. This is in line with the findings of Glaeser and Saiz (2001) that show how consumption opportunities can attract urban clusters of high skill workers. Lee adds to this line of thinking, showing how these workers may have a rational reason for doing so at a lower wage.

Building from these studies and literature, our research examines the effects of the distribution of human capital between cities and suburbs on regional economic performance. The next section details our methodology for doing so.

\section{Model, Variables and Methods}

This section describes our model, variables, data and methods. We begin with our general model. The model is based on the core concepts and theory outlined above. It is designed to empirically test how the distribution of human capital affects regional economic performance. To do so, we compare two different models using the same variables and data. The first model explains regional economic 
performance based on the average level of human capital across the entire metro. The second explains regional economic performance based on the shares of human capital made up of by the center city versus its surrounding suburbs. This gives us two versions of a similar relationship:

(Model a) Economic Performance $=\alpha+\beta_{1}$ Metro level $+\varepsilon$

(Model b) Economic Performance $=\alpha+\beta_{21}$ City Center level $+\beta_{22}$ Suburb level $+\varepsilon$

\section{Variables}

The key distinction in this analysis is separating the "city" and the "suburb" in a metropolitan area. Our data is based on the conventional U.S. Metropolitan Statistical Area (MSA) designation from the 2000 Census as defined by the Office of Management and Budget (US OMB, FIPS-55 standard). Only MSAs, or what we refer to as metropolitan areas or metros are analyzed. Each MSA is spatially divided into "central city[s]" and the remainder. The remainder is designated "suburb," The central city is identified in the geographic header of the 2000 Census Summary File 3 (SF3). The definition used is the one provided by the US Census Bureau:

“[T]he largest place and, in some cases, one or more additional places are designated as "central cities" under the official standards. A few primary metropolitan statistical areas do not have central cities. ... An MA [metropolitan area] central city does not include any part of that place that 
extends outside the MA boundary." Summary File 3 Technical Documentation, U.S. Census Bureau, 2000 [issued 2003], U.S. Department of Commerce: Washington D.C., pp. A-16-A-17.

Once the central city and suburbs have been identified, total area for each is calculated. Both land and water area is included. The individual variable values and densities (discussed below) are then calculated for the city and suburban portions of each MSA.

We populate the model with the following dependent and independent variables.

\section{Dependent Variables}

We employ two commonly used measures of regional economic performance, average incomes and median housing values.

Average Income: Average income captures regional wealth based on wages and salaries. This is perhaps the single best measure of the economic status regional populations relative to one another. Average income includes wage and salary income including net self-employment income; interest, dividends, or net rental or royalty income or income from estates and trusts; social security or railroad retirement income; Supplemental Security Income (SSI); public assistance or welfare 
payments; retirement, survivor, or disability pensions; and all other income . It is measured on a per capita basis.

Median Housing Value: This is perhaps the best available measure for the relative demand for space across regions. It tells how much households are willing to pay for housing in the region. Median housing value is the standard measure of housing value. For metros that cross state borders, we calculate separate medians for each state and calculate a weighted average of the medians using the number of owner-occupied houses valued.

\section{Independent Variables:}

Metro Human Capital Share: The conventional measure of human capital is based on the percentage of adults with a bachelor's degree and above. Here we use the standard measure of regional human capital based on the percentage of adults (age 25 and older) in a metro with a bachelor's degree or above.

Center City Human Capital Share: This variable captures the share of adults with a bachelor's degree or above located in the center city.

Suburban Human Capital Share: This variable captures the share of adults with a bachelor's degree or above located in the suburbs surrounding the center city. 
Human Capital Density: This variable is the number of adults with a bachelor's degree or above per square kilometer.

Center City Human Capital Density: This variable captures the number of adults with a bachelor's degree or above per square kilometer in the center city.

Suburban Human Capital Density: This variable captures the number of adults with a bachelor's degree or above per square kilometer in the suburbs surrounding the center city.

Population Density: This variable is the number of individuals per square kilometer.

Center City Population Density: This variable captures the total number of residents per square kilometer in the center city.

Suburban Population Density: This variable captures the total number of residents per square kilometer in the suburbs surrounding the center city.

The variables and data-set cover 331 metropolitan statistical areas across the U.S. and are for the year 2000 from the US Census. Descriptive statistics for the variables are provided in Table 1. Appendix Table A provides descriptive statistics 
for the variables across four regional size groups - metros with over one million people (size 1), those between 500,000 and one million people (size 2), regions with 250,000-500,000 people (size 3), and regions under 250,000 people (size 4).

\section{(Table 1 about here)}

\section{Methods}

Our analysis is based on a combination of bivariate correlation analysis and multivariate regression. We include separate regressions for our two dependent variables - average income and median housing value. Based on the model outlined above, we run regressions at the overall metro level first, and then follow with separate regressions which split the human capital variable into center city and suburban shares. To test for region size effects, we also run the regressions for four different size classes of regions: those with million people (size 1); 500,000 to 1 million (size 2); 250,000 to 500,000 (size 3); and less than 250,000 (size 4). In the regressions, all variables are logged and the coefficients are thereby expressed as elasticities.

\section{Findings}

To orient the analysis, we start with the results of a simple bivariate correlation analysis (see Table 2, Appendix Table B presents the correlation results for the metro size groups).

\section{(Table 2 about here)}


The results of the correlation analysis, not surprisingly, reveal a close association between human capital and both average income and median housing value at the metropolitan level, with correlations of .676 and .628 respectively. The correlations become just slightly lower when we employ human capital density, .644 for average income and .576 for median housing value. In both instances, the correlations for the metro-level human capital measures are higher than for the metro-level population density measures, .502 and .454 respectively.

We now split the data set by center city and suburban human capital shares. Turning first to income, the highest correlation is for suburban human capital (.783) share which is somewhat higher than metro-level human capital (.676) and substantially higher than for center city human capital share (.298). The measure for suburban human capital density (.651) also outperforms that for metro human capital density (.502) and center city human capital density (.454) although the measure of center city human capital density performs relatively better than for center city human capital share as per above.

Turning now to median housing values, we find a more muted pattern. The highest correlation is again for suburban human capital share (.678), but it is only slightly better than for metro-level human capital share (.628) and center city share (.584). The pattern changes somewhat when we employ measures of human capital density. Now the correlations for all three measures - suburb, center-city and metrolevel are all relatively similar. The correlation for center city human capital is highest 
(.584) by a nose, followed by metro-level human capital density (.576) and then suburban human capital density (.567).

The next question is how metro, center city and suburb human capital levels might be related to one another. Figure 1 provides two scatter-plots for this relationship, one for shares, the other for density.

\section{(Figure 1 about here)}

The scatter-plots show a clear positive and significant relationship between human capital shares in city centers and suburbs on both scores, with a correlation of .405 based on population and .446 based on density. In other words, higher levels of human capital in city centers increase the probability of finding higher levels also in the suburbs and vice versa. However, the relationship between human capital in city centers and suburbs is not perfectly linear, and does not include exactly the same information. The relationship between the metro averages and the center shares and density levels are not surprisingly more linear (given that the metro average to a certain extent is a function of the centers), with correlations of .706 versus .495. In other words, we find a stronger relation between the human capital shares between centers and metros on average, than we do for the relation between human capital density in metros and centers.

While the bottom two scatter plots (Figure 1) show the expected relationship between metropolitan and center city human capital, the top two show that, while 
very weakly correlated, there is a great deal of variation across metropolitan areas in both central city and suburban human capital and human capital density. Further, the weak correlation shows that for any given city the urban and suburban values are generally independent of each other. This variation means that investigating these relationships is likely to generate interesting results.

\section{Regression Results}

We now turn to the results of our regression models. Based on the model outlined above, we run separate regressions for average income and median housing value. We analyze the models based on metro average shares and density levels first, followed by separate models which distinguish between city center and suburban human capital. We also run the analysis for four regional size classes: regions over a million population (size 1); 500,000 to 1 million (size 2); 250,000 to 500,000 (size 3); and less than 250,000 (size 4), to capture if center city and suburban shares play different roles based on region size. (An appendix reports the results for all regions in models that include regional size dummies to check for any results that may be the result of the smaller number of regions that populate the regional size groups).

The models examine the effects of human capital shares and density on average income and median housing values. We run each regression for all regions and each size class. At top of each table, we illustrate the results for the regressions where metro averages are used as explanatory variables. Below, we illustrate the 
regression results where the dependent variable is explained by the distribution of human capital shares and density between city centers and suburbs. We also run population density regressions to rule out that human capital is not just a proxy for population density. The population density regression results are detailed in the appendix, but we report for the key results in the text below. Additionally, we control for the share of the land area the metro centers make up. We add this control variable to the regressions based on Model B which splits up center and suburb human capital levels. We report in footnotes under each table for the cases where this control variable is significant.

\section{Results for Median Income}

We start with the results for the regressions for median income summarized in Table 3.

\section{(Table 3 about here)}

The results for these regressions suggest that the distribution of human capital within metropolitan areas matters. Save for one case - large regions with more than 1 million in population (eq 2), the R2 values increase when we split metro human capital into center city and suburban shares. The R2 for the overall regression for all region increases from .457 to .610, while the R2s for the regressions for small and medium size regions also increase, going from .559 to .754 for size 2 regions, from .527 to .638 for size 3 regions, and from .293 to .487 for size 4 . 
Also of interest is the pattern of results for the variables for center city and suburban human capital share. The variable for suburban share is significant in the models for all regions and for each of the region size classes. The variable for center city share is significant in only one case, large regions (size 1), those with over one million people. As this was the only regression where R2 was reduced by splitting human capital, it may be a spurious result. It is also possible that only the largest regions have a large enough core with sufficient human capital to influence the relationship. The latter explanation is somewhat supported by looking at Table A in the Appendix which shows that the average share of human capital is higher in the central cities of largest metropolitan areas than all the other size categories.

However, the suburban densities as well as the human capital shares in centers and suburbs remain approximately at the same level.

We now turn the findings for income and human capital density (see Tables $4)$.

\section{(Table 4 about here)}

The results echo the pattern above to some degree. Overall, the distribution of human capital density within regions matters significantly to regional incomes. Again the R2 values increase when metro human capital density is split between center and suburb human capital density. This increase is .415 to .464 for all regions, from .316 to .328 for size 1 regions, from .150 to .330 for size 2 regions, from .388 to 
.441 for size 3 regions and from .333 to .423 for size 4 regions. But, the findings here suggest a slightly different pattern in terms of the relative strength of the center city and suburban densities of human capital. Whereas the suburban share of human capital was dominant in the models above, now using the density measure, both center city and suburban shares are significant in the models for all regions and for size 2 through 4 regions. Furthermore, center city human capital density outperforms suburban human capital density for large (size 1) regions, being significant while suburban human capital density is not. This indicates both city and suburban human capital density matter to regional incomes for all size classes of regions. In the largest regions (those with more than 1 million in population) and those with 500,000 to 1 million (size 2) and under 250,000 (size 4) center human capital density explains more than suburban human capital density.

To rule out that human capital is not just a proxy for population, we re-run the regressions but substitute human capital density with population density (see appendix $C$ for these results). The regressions for population density generate significantly lower R2 values than the human capital density regressions above. Metro population density is significant in all cases but for size 2 regions (eq 3a). Splitting population density into center and suburb population density does not add much explanatory value, as the $\mathrm{R} 2$ values are about the same as in the regression using overall metro-level population density. Both center city population density and suburban population density are significant in the model for all regions. When we parse the sample by region size, the results are weaker and mixed. For large 
regions, only suburban population density is weakly significant. For regions between 250,000 and 500,000 (size 3) and those under 250,000 (size 4) suburban population density is significant. Neither central city nor suburban population density is significant in the model for medium-size regions (size 2) between 500,000 and one million people. We also ran the same series of regressions for the entire metro level sample but using dummy variables for regional size, to check whether our results were affected by the smaller sizes of some regional groups. The results, summarized in Appendix Table $\mathrm{D}$, are in line with the results above.

\section{Results for Median Housing Values}

This section presents the results for the regressions for median housing values. We begin with the regressions for human capital shares which we summarize in Table 5.

\section{(Table 5 about here)}

Generally speaking, the pattern for these regressions mimics those of the regressions for regional incomes (see Table 3), with one caveat: Human capital explains less of median housing values than it does for regional income. Metro level human capital is positively associated with regional housing values in each and every model, for all regions and for each of the four size groupings. Again, when we split human capital into its center city and suburban shares, the $\mathrm{R} 2$ values increase slightly in four of the five models - for all regions and for size 2, 3 and 4 regions, but 
not for larger, size 1 regions. And like the earlier analysis, suburban human capital provides more explanatory power in these models. Suburban human capital share is significant in the regressions for al metros and size 2, 3 and 4 regions. As earlier, center city human capital is significant only in the largest (size 1) regions.

We can expect a positive relationship between density and housing values, since density itself is likely to result when housing values are high or when expansion at the periphery is not possible or restricted. We now present the results for our regressions of human capital density and median housing values (see Table $6)$.

\section{(Table 6 about here)}

The key results for these regressions are similar to those for the earlier regressions on human capital density and income (see Table 4). Human capital density has a positive and significant relation to median housing values for all regions and for all regional sizes. However, we note the stronger explanatory power for size 1 regions where the $\mathrm{R} 2$ is .361, than in smaller and medium-size regions where the R2s range from .150 to .177 . Again splitting human capital density into its city and suburban shares adds significantly to the explanatory power of the models in four of five cases - in all the regressions except that for the largest ( size 1) regions where the $\mathrm{R} 2$ increase is more minor. For all regions, the R2 increases from .332 to .465 , for size 2 regions it improves from .177 to .306 , for size 3 regions it grows from .204 to .450 (eq 4), and for size 4 regions it increase from .150 to .347 . In contrast to the 
result for the share of human capital (Table 5) the results for these density regressions indicate that city centers play a more important role when it comes to human capital density. Center city human capital density is significant in all five regressions, and it is also stronger than the variable for suburban human capital density. It appears that center city human capital density has a more substantial effect on regional housing values - which makes intuitive sense since density itself may be a function of higher housing values. This explanation is also supported by the fact that suburban human capital density is insignificantly related with median housing values in the largest (size 1) regions.

To once more rule out that human capital density is not just a proxy for population density, we re-run these regressions, but with population density as explanatory variable (see Appendix Table E for these results). Generally speaking, population density explains less of median housing value than human capital density, and the R2s are smaller across the board. Metro population density is positive and significant for all regions and for each and every of the regional size groups. The R2 values are higher for or all regions (eq 1) and large (size 1) regions (eq 2) and fall of considerably in smaller regions. Splitting population density into center city and suburban population density has little effect on the R2 values, and the R2 levels remain low for small and medium size regions, suggesting that population density explains very little, and considerably less than human capital density. We also ran the same regression for all regions but with dummy variables for regional size (see Appendix Table F). The results are in line with those above. 


\section{Conclusion and Discussion}

Human capital has been identified as the key driver of regional economic growth and development. A wide body of empirical research has documented the close relationship between human capital and regional economic performance (Florida, 2002; Berry and Glaeser, 2005; Florida et al., 2008). But while theory suggests that the distribution of human capital within regions is likely to matter, empirical research has largely ignored this issue. On the one hand, a significant body of research (Shapiro, 2005; Gyourko et al., 2006) suggests that incomes and housing values will rise in metros with denser levels of human capital in the center city. On the other hand, many suburbs are location of choice for high-skill, high-income, high human capital individuals and households.

Our research took up this question of the effects of the distribution of human capital between city centers and suburbs on regional economic performance. We ran regression models to examine the effects of the distribution of human capital controlling for other factors on two key measures of regional economic performance, average incomes and median housing values.

Our key findings suggest that the distribution of human capital matters to regional economic performance. First and foremost, in virtually all permutations of our models, the results are stronger when we separate center city and suburban shares rather than for metro-level human capital overall. These results show that the 
concentration of human capital in central cities and suburbs impacts regional income differently. The density results show that it's not just the concentration of human capital that is important, but also the relative proximity of these high skilled individuals. The income results are in line with the earlier finding of Lee (2010) that central cities need not necessarily support higher wages because residents also gain utility from the diversity of consumption opportunities available in central cities. In suburban areas, incomes have to be higher to compensate the highly skilled for lacking consumption opportunities.

Second, the findings further suggest that suburban human capital plays substantial role. While theory suggests that concentration of human capital at the center should matter (esp. Jacobs, 1969; Lucas, 1988), the findings indicate that the suburban human capital share is more strongly related to regional income and housing values. This is true for the models for all regions and especially for smaller and medium sized metros. Because of their population size (under one million), most of these smaller and medium size regions require less density. They can grow and develop in a less concentrated pattern, and can support much more fluid and less congested commuting and transportation patterns. Central locations are likely to be less valued by higher-skill, higher income individuals and households. Regional economic performance in these locations does not depend on concentration and density as much as in largest regions.

Third, we find that center city human capital plays a more significant role in the largest metros, those with more than one million people. For the largest regions 
(those with more than a million people), the variable for center city human capital share explains more of regional income than does that for the suburbs. This result is reinforced by the findings of the regressions for human capital density as well. This makes sense intuitively and brings us back into line with what we would expect per urban theory (esp. Jacobs 1969; Lucas, 1988). Larger regions, by virtue of their size, require denser patterns to accommodate population growth. They are the regions that suffer most from traffic congestion and burdensome commuting patterns. They are more likely to see considerable premiums for central locations. For these reasons, higher-skill, higher-income families are more likely to prefer central locations in these regions. Our results indicate that when the size threshold of a million people is crossed, the effects of more highly concentrated and dense human capital at the city center really comes into play. Human capital densities increase markedly for metros with more than 3 million people, though the number of these regions is too small to generate statistically reliable results. Metros with more than 3 million people have human capital density of 443 high human capital people per square kilometer compared to 227 high human capital people per square mile for metros between 1 an 3 million people. Human capital in city centers thus appears to play a more pronounced role in regional economic performance for large regions.

Generally speaking, this research compares the impact of human capital on regional outcomes in three dimensions. The first is a spatial dimension investigating central cities and suburbs. The second looks at the intensity of human capital by analyzing the impact from both concentration (share) and density. Finally, these 
relationships are investigated at an overall level and within population-based size groups. The spatial dimension is always found to be significant. Separating central cities and suburbs generates significant results and increases the explanatory power of the models. The spatial dimension is stronger when investigating regional income levels than for housing value, but remains important. The impact of the intensity of human capital shows similar patterns for regional income and housing values. The concentration or share of suburban human capital is positively related to increased incomes and housing values while the share within central cities doesn't have much of a relationship. However, when the intensity is ramped up, the density of human capital in central cities generally outperforms suburban human capital density. For housing values, suburban human capital density has a more mixed result. When the results for the final dimension (region size) are considered, income levels and housing values reveal different relationships. For income, the largest regions (those over 1 million) reflect an importance for central city human capital that does not show up for the smaller regions. For housing values, the situation is reversed. Region size interacts with both intensity and location such that metro areas under 1 million show increases in housing values associated with suburban human capital density.

Overall our findings indicate that the distribution of human capital within regions matters greatly to regional economic performance. One limitation of our analysis is that it deals with human capital based on residence. Findings may differ if place of work is used. Indeed we might expect to find stronger central city effects. 
We encourage more research which contrasts intra-metropolitan human capital between place of residence and place of work. Most of all, we hope our initial research on this question will encourage further empirical work on this important subject. 


\section{References:}

Barro, R. J. (1991) Economic Growth in a Cross Section of Countries, Quarterly Journal of Economics, 106(2): 407-443.

Barro, R. J. (1997) Determinants of Economic Growth: A Cross-Country Empirical Study, Cambridge, MA: The MIT Press

Berry, C. R., Glaeser, E. L. (2005) The Divergence of Human Capital Levels Across Cities, NBER Working Paper No. 11617, September 2005.

Florida, R. (2002a) The Rise of the Creative Class, New York: Basic Books.

Florida, R. (2002b) The Economic Geography of Talent, Annals of the Association of American Geographers, 92(4): 743-755.

Florida, R. (2002c) Bohemia and economic geography, Journal of Economic Geography, 2: 55-71.

Florida, R., Mellander, C., Stolarick, K. (2008) Inside the Black Box of Regional Development, Journal of Economic Geography, 8: 615-649

Florida, R., Mellander, C. (2010) There Goes the Metro: How and Why Artists, Bohemians and Gays Affect Housing Values, Journal of Economic Geography, 2: 167188.

Glaeser, E. L. (2000) The new economics of urban and regional growth, In The Oxford handbook of economic geography, ed Gordon, C., Meric, G., Feldman, M, 83-98, Oxford: Oxford University Press.

Glaeser, E. L., Kolko, J., Saiz, A. (2001) Consumer City, Journal of Economic Geography, $1: 27-50$.

Glaeser, E. L., Saiz, A. (2003) The Rise of the Skilled City, NBER Working Papers no 10191, National Bureau of Economic Research, Inc.

Gyourko, J., Mayer, C., Sinai, T. (2006) Superstar Cities, NBER Working Paper No 12355, July 2006

Jacobs, J. (1969) The Economies of Cities, New York: Random House.

Kotkin, J. (2000) The new geography, New York: Random House. 
Lucas, R. (1988) On the Mechanics of Economic Development, Journal of Monetary Economics, 22: 3-42.

Rauch, J. (1993) Productivity Gains from Geographic Concentration of Human Capital: Evidence from the Cities, Journal of Urban Economics, 34: 380-400.

Samuelson, P. A., Nordhaus,W. D. (2004) Economics, $18^{\text {th }}$ ed., New York: McGrawHill.

Shapiro, J. M. (2006) Smart Cities: Quality of Life, Productivity, and the Growth Effects of Human Capital, The Review of Economics and Statistics, 88(2): 324-335.

Simon, C., Nardinelli, C. (1996) The Talk of the Town: Human Capital, Information and the Growth of English Cities, 1861-1961, Explorations in Economic History, 33(3): 384-413

Simon. C. (1998) Human capital and metropolitan employment growth, Journal of Urban Economics, 43:223-43

Smith, A. (1776) The Wealth of Nations, New York: Random House (2000)

Tiebout, C. M. (1956) A Pure Theory of Local Expenditures, The Journal of Political Economy, 64:2, pp 416-424.

Ullman, E. L. (1958) Regional development and the geography of concentration, Papers and proceedings of the Regional Science Association, 4:179-98. 
Table A: Descriptive Statistics by Region Size

\begin{tabular}{|c|c|c|c|c|c|c|c|c|c|c|}
\hline & \multicolumn{5}{|c|}{ Size 1} & \multicolumn{5}{|c|}{ Size 2} \\
\hline & $\mathbf{N}$ & $\begin{array}{c}\text { Minimu } \\
\mathbf{m}\end{array}$ & $\begin{array}{c}\text { Maximu } \\
\text { m }\end{array}$ & Mean & $\begin{array}{l}\text { Std. } \\
\text { Dev. }\end{array}$ & $\mathbf{N}$ & $\begin{array}{c}\text { Minim } \\
\text { um }\end{array}$ & $\begin{array}{c}\text { Maxim } \\
\text { um }\end{array}$ & Mean & $\begin{array}{l}\text { Std. } \\
\text { Dev. }\end{array}$ \\
\hline Average Income & 61 & 182967 & 39796 & 24368 & 4124 & 42 & 9848 & 27593 & 20799 & 3297 \\
\hline Median Housing & 61 & 78916 & 502011 & 16210 & 80955 & 42 & 51302 & 286601 & 12218 & 45778 \\
\hline Value & & & & 9 & & & & & 8 & \\
\hline Average Metro HC & 61 & .16 & .44 & .28 & .058 & 42 & .13 & .37 & .24 & .052 \\
\hline Metro HC Density & 61 & 2.08 & 522.39 & 69.87 & 84.36 & 42 & 2.52 & 654.17 & 37.97 & 98.97 \\
\hline $\begin{array}{l}\text { Metro Population } \\
\text { Density }\end{array}$ & 61 & 19.22 & 2711.18 & 362.74 & 424.85 & 42 & 32.13 & 3854.40 & 235.99 & 579.32 \\
\hline Average Center HC & 57 & .09 & .46 & .27 & .08 & 42 & .09 & .69 & .24 & .09 \\
\hline Center HC Density & 57 & 43.73 & 1418.15 & 272.27 & 218.07 & 42 & 40.38 & 645.89 & 177.31 & 123.51 \\
\hline $\begin{array}{l}\text { Center Population } \\
\text { Density }\end{array}$ & 57 & 285.16 & 7817.14 & $\begin{array}{c}1648.0 \\
6\end{array}$ & $\begin{array}{c}1227.2 \\
4\end{array}$ & 42 & 351.46 & 3767.96 & $\begin{array}{c}1174.4 \\
4\end{array}$ & 594.19 \\
\hline $\begin{array}{l}\text { Average Suburb } \\
\text { HC }\end{array}$ & 61 & .16 & .50 & .29 & .06 & 42 & .07 & .35 & .23 & .06 \\
\hline $\begin{array}{l}\text { Suburb HC } \\
\text { Density }\end{array}$ & 61 & 1.39 & 265.80 & 51.41 & 59.36 & 42 & 1.20 & 662.70 & 31.69 & 100.88 \\
\hline $\begin{array}{l}\text { Suburb Population } \\
\text { Density }\end{array}$ & 61 & 13.38 & 1475.31 & 254.09 & 282.61 & 42 & 15.35 & 3943.34 & 192.52 & 597.08 \\
\hline \multirow[t]{3}{*}{ Valid N (listwise) } & 57 & & & & & 42 & & & & \\
\hline & \multicolumn{5}{|c|}{ Size 3} & \multicolumn{5}{|c|}{ Size 4} \\
\hline & $\mathbf{N}$ & $\begin{array}{c}\text { Minimu } \\
\mathrm{m}\end{array}$ & $\begin{array}{c}\text { Maximu } \\
\text { m }\end{array}$ & Mean & $\begin{array}{l}\text { Std. } \\
\text { Dev. }\end{array}$ & $\mathbf{N}$ & $\begin{array}{c}\text { Minim } \\
\text { um }\end{array}$ & $\begin{array}{c}\text { Maxim } \\
\text { um }\end{array}$ & Mean & $\begin{array}{l}\text { Std. } \\
\text { Dev. }\end{array}$ \\
\hline Average Income & 79 & 11140 & 52618 & 21513 & 5100 & 149 & 10371 & 34735 & 19637 & 3183 \\
\hline Median Housing & 79 & 58630 & 465154 & 12766 & 70987 & 149 & 50310 & 260489 & 10071 & 35262 \\
\hline Value & & & & 9 & & & & & 1 & \\
\hline Average Metro HC & 79 & .11 & .52 & .23 & .075 & 149 & .11 & .48 & .22 & .079 \\
\hline Metro HC Density & 79 & 1.88 & 171.20 & 21.29 & 27.74 & 149 & .36 & 55.73 & 10.20 & 9.91 \\
\hline $\begin{array}{l}\text { Metro Population } \\
\text { Density }\end{array}$ & 79 & 20.59 & 643.82 & 127.41 & 116.20 & 149 & 2.16 & 373.42 & 69.64 & 53.51 \\
\hline Average Center HC & 79 & .09 & .51 & .23 & .092 & 148 & .04 & .69 & .25 & .105 \\
\hline Center HC Density & 79 & 9.10 & 433.07 & 140.69 & 84.88 & 148 & 20.61 & 642.26 & 121.05 & 85.82 \\
\hline $\begin{array}{l}\text { Center Population } \\
\text { Density }\end{array}$ & 79 & 51.24 & 4041.14 & $\begin{array}{c}1105.2 \\
9\end{array}$ & 825.69 & 148 & 225.17 & 3266.14 & 828.20 & 435.81 \\
\hline $\begin{array}{l}\text { Average Suburb } \\
\text { HC }\end{array}$ & 78 & .09 & .66 & .23 & .09 & 149 & .04 & .46 & .20 & .07 \\
\hline $\begin{array}{l}\text { Suburb HC } \\
\text { Density }\end{array}$ & 78 & .72 & 142.68 & 16.20 & 25.66 & 149 & .04 & 47.64 & 5.99 & 7.92 \\
\hline $\begin{array}{l}\text { Suburb Population } \\
\text { Density }\end{array}$ & 78 & 9.74 & 482.26 & 88.48 & 90.58 & 149 & 1.20 & 226.16 & 40.61 & 36.18 \\
\hline Valid N (listwise) & 78 & & & & & 148 & & & & \\
\hline
\end{tabular}


Table B - Correlation Results per Metro Size

\begin{tabular}{|c|c|c|c|c|}
\hline & \multicolumn{2}{|c|}{ Size 1} & \multicolumn{2}{|c|}{ Size 2} \\
\hline & $\begin{array}{l}\text { Average } \\
\text { Income }\end{array}$ & $\begin{array}{c}\text { Median } \\
\text { Housing Value } \\
\end{array}$ & $\begin{array}{l}\text { Average } \\
\text { Income }\end{array}$ & $\begin{array}{c}\text { Median } \\
\text { Housing Value } \\
\end{array}$ \\
\hline Metro HC Share & $.791^{* * * *}$ & $.637^{* * * *}$ & $.748^{* * *}$ & $.516^{* * *}$ \\
\hline Metro HC Density & $.562^{* * *}$ & $.601^{* * *}$ & $.387^{* * *}$ & $.420^{* * *}$ \\
\hline Metro Population Density & $.423^{* * *}$ & $.516^{* * *}$ & .163 & $.295^{*}$ \\
\hline Center City HC Share & $.463^{* * *}$ & $.407^{* * * *}$ & $.331^{* *}$ & $.313^{* *}$ \\
\hline Center City HC Density & $.540^{* * *}$ & $.602^{* * *}$ & $.454^{* * *}$ & $.489^{* * * *}$ \\
\hline Center Population Density & $.296^{* * *}$ & $.395^{* * *}$ & $.258^{*}$ & $.316^{* *}$ \\
\hline Suburb HC Share & $.724^{* * * *}$ & $.594^{* * *}$ & $.867^{* * *}$ & $.564^{* * *}$ \\
\hline Suburb HC Density & $.556^{* * *}$ & $.558^{* * *}$ & $.510^{* * *}$ & $.440^{* * *}$ \\
\hline \multirow[t]{3}{*}{ Suburb Population Density } & $.448^{* * *}$ & $.493^{* * *}$ & .237 & $.297^{*}$ \\
\hline & \multicolumn{2}{|r|}{ Size 3} & \multicolumn{2}{|r|}{ Size 4} \\
\hline & $\begin{array}{l}\text { Average } \\
\text { Income }\end{array}$ & $\begin{array}{c}\text { Median } \\
\text { Housing Value } \\
\end{array}$ & $\begin{array}{l}\text { Average } \\
\text { Income }\end{array}$ & $\begin{array}{c}\text { Median } \\
\text { Housing Value } \\
\end{array}$ \\
\hline Metro HC Share & $.726^{* * *}$ & $.674^{* * *}$ & $.541^{* * * *}$ & $.560^{* * *}$ \\
\hline Metro HC Density & $.623^{* * * *}$ & $.451^{* * *}$ & $.577^{* * *}$ & $.388^{* * *}$ \\
\hline Metro Population Density & $.395^{* * *}$ & $.245^{* *}$ & $.391^{* * * *}$ & $.191^{* *}$ \\
\hline Center City HC Share & $.209^{*}$ & $.230^{* *}$ & $.287^{* * *}$ & $.382^{* * *}$ \\
\hline Center City HC Density & $.322^{* * * *}$ & $.530^{* * *}$ & $.397^{* * *}$ & $.467^{* * *}$ \\
\hline Center Population Density & .165 & $.383^{* * *}$ & $.186^{* *}$ & $.233^{* * *}$ \\
\hline Suburb HC Share & $.798^{* * *}$ & $.697^{* * * *}$ & $.691^{* * *}$ & $.621^{* * *}$ \\
\hline Suburb HC Density & $.610^{* * *}$ & $.406^{* * *}$ & $.570^{* * *}$ & $.424^{* * *}$ \\
\hline Suburb Population Density & $.377^{* * *}$ & $.192^{*}$ & $.391^{* * *}$ & $.262^{* * *}$ \\
\hline
\end{tabular}


Table C- Regional Income and Population Density

\begin{tabular}{|c|c|c|c|c|c|}
\hline \multicolumn{6}{|c|}{ Av Metro Population Density (a-regressions) } \\
\hline Variables & Eq 1a. All regions & Eq 2a. Size 1 & Eq 3a. Size 2 & Eq 4a. Size 3 & Eq5a.Size 4 \\
\hline \multirow[t]{2}{*}{ Constant } & $9.492^{* * *}$ & $9.645^{* * *}$ & $9.749^{* * *}$ & $9.400^{* * *}$ & $9.558^{* * *}$ \\
\hline & $(218.442)$ & $(77.074)$ & $(56.016)$ & (63.218) & $(153.837)$ \\
\hline \multirow[t]{2}{*}{ Metro Pop Density } & $0.199 * * *$ & $0.080^{* * *}$ & 0.037 & $0.121^{* * *}$ & $0.079^{* * *}$ \\
\hline & (10.516) & $(3.583)$ & $(1.043)$ & $(3.768)$ & $(5.158)$ \\
\hline Observations & 331 & 61 & 42 & 79 & 149 \\
\hline $\mathrm{R} 2$ & 0.252 & 0.179 & 0.026 & 0.156 & 0.153 \\
\hline \multicolumn{6}{|c|}{ Center and Suburb Population Density (b-regressions) } \\
\hline Variables & Eq 1b. All regions & Eq 2b. Size 1 & Eq 3b. Size 2 & Eq 4b. Size 3 & Eq 5b. Size 4 \\
\hline \multirow[t]{2}{*}{ Constant } & $9.353^{* * *}$ & $9.609^{* * *}$ & $9.296^{* * *}$ & $9.368^{* * *}$ & $9.366^{* * *}$ \\
\hline & (93.556) & (44.817) & (22.235) & (42.812) & (59.825) \\
\hline Center City Pop & $0.046^{* * *}$ & 0.030 & 0.073 & 0.035 & $0.046^{* *}$ \\
\hline Density & $(2.850)$ & $(0.807)$ & $(1.091)$ & $(1.050)$ & $(1.981)$ \\
\hline Suburb Pop & $0.068^{* * *}$ & $0.049^{*}$ & 0.028 & $0.083^{* * *}$ & $0.060^{* * *}$ \\
\hline Density & $(7.753)$ & (1.757) & $(0.867)$ & $(2.976)$ & $(4.972)$ \\
\hline Observations & 326 & 58 & 43 & 79 & 149 \\
\hline $\mathrm{R} 2$ & 0.249 & 0.137 & 0.084 & 0.155 & 0.175 \\
\hline
\end{tabular}


Table D--Regressions with dummies for metro size (either $>1 \mathrm{M}$ or $<250 \mathrm{~K}$ )

\begin{tabular}{|c|c|c|c|c|c|c|}
\hline Variables & $\begin{array}{c}E q 1 \\
\text { HC Share }\end{array}$ & $\begin{array}{c}E q 2 \\
\text { HC Share }\end{array}$ & $\begin{array}{c}E q 3 \\
\text { HC Density }\end{array}$ & $\begin{array}{c}E q 4 \\
\text { HC Density }\end{array}$ & $\begin{array}{c}\text { Eq } 5 \\
\text { Pop } \\
\text { Density }\end{array}$ & $\begin{array}{c}\text { Eq } 6 \\
\text { Pop } \\
\text { Density }\end{array}$ \\
\hline Constant & $\begin{array}{l}10.498^{* * *} \\
(265.767)\end{array}$ & $\begin{array}{l}10.501^{* * *} \\
(310.203)\end{array}$ & $\begin{array}{c}9.650^{* * *} \\
(340.691)\end{array}$ & $\begin{array}{c}9.403^{* * *} \\
(155.705)\end{array}$ & $\begin{array}{c}9.576^{* * *} \\
(169.920)\end{array}$ & $\begin{array}{l}9.432^{* * *} \\
(87.983)\end{array}$ \\
\hline MSA HC Share & $\begin{array}{l}0.371^{* * *} \\
(14.695)\end{array}$ & & & & & \\
\hline Center HC Share & & $\begin{array}{c}-0.009 \\
(-0.475)\end{array}$ & & & & \\
\hline Suburb HC Share & & $\begin{array}{l}0.372^{* * *} \\
(18.297)\end{array}$ & & & & \\
\hline MSA HC Density & & & $\begin{array}{l}0.107^{* * *} \\
(11.754)\end{array}$ & & & \\
\hline Center HC Share & & & & $\begin{array}{c}0.078^{* * *} \\
(6.095)\end{array}$ & & \\
\hline Suburb HC Share & & & & $\begin{array}{l}0.072^{* * *} \\
(10.041)\end{array}$ & & \\
\hline MSA Pop Density & & & & & $\begin{array}{c}0.079^{* * *} \\
(6.789)\end{array}$ & \\
\hline Center Pop & & & & & & $0.039^{* *}$ \\
\hline Density & & & & & & $(2.426)$ \\
\hline Suburb Pop & & & & & & $0.057^{* * *}$ \\
\hline Density & & & & & & $(5.686)$ \\
\hline Big MSA Dummy & $\begin{array}{c}0.071^{* * *} \\
(3.284)\end{array}$ & $\begin{array}{l}0.039^{* *} \\
(2.055)\end{array}$ & $\begin{array}{c}0.033 \\
(1.361)\end{array}$ & $\begin{array}{c}0.014 \\
(0.584)\end{array}$ & $\begin{array}{c}0.079^{* * *} \\
(2.914)\end{array}$ & $\begin{array}{c}0.071^{* * * *} \\
(2.626)\end{array}$ \\
\hline Small MSA & $-0.45^{* * *}$ & -0.013 & 0.014 & 0.026 & -0.016 & -0.007 \\
\hline Dummy & $(-2.735)$ & $(-0.883)$ & $(0.720)$ & (1.427) & $(-0.751)$ & $(-0.346)$ \\
\hline Observations & 333 & 328 & 333 & 328 & 333 & 328 \\
\hline $\mathrm{R} 2$ & 0.502 & 0.619 & 0.419 & 0.468 & 0.275 & 0.268 \\
\hline
\end{tabular}

***Indicates significance at the 0.01 level; ${ }^{* *}$ at the 0.05 level; ${ }^{*}$ at the 0.10 level. 
Table E- Regional Housing Values and Population Density

\begin{tabular}{|c|c|c|c|c|c|}
\hline \multicolumn{6}{|c|}{ Av Metro Population Density } \\
\hline Variables & Eq 1a. All regions & Eq 2a. Size 1 & Eq 3a. Size 2 & Eq $4 a$. Size 3 & Eq 5a. Size 4 \\
\hline \multirow[t]{2}{*}{ Constant } & $10.778^{* * *}$ & $10.548^{* * *}$ & $11.069^{* * *}$ & $10.941^{* * *}$ & $11.167^{* * *}$ \\
\hline & $(116.095)$ & $(35.465)$ & $(36.303)$ & $(33.595)$ & $(85.278)$ \\
\hline \multirow[t]{2}{*}{ Metro Pop Density } & $0.186^{* * *}$ & $0.246^{* * *}$ & $0.120^{*}$ & $0.155^{* * *}$ & $0.076^{* *}$ \\
\hline & $(9.252)$ & $(4.624)$ & $(1.956)$ & $(2.215)$ & $(2.355)$ \\
\hline Observations & 331 & 61 & 42 & 79 & 149 \\
\hline $\mathrm{R} 2$ & 0.206 & 0.266 & 0.087 & 0.060 & 0.036 \\
\hline \multicolumn{6}{|c|}{ Center and Suburb Population Density } \\
\hline Variables & Eq 1b. All regions & Eq 2b. Size 1 & Eq $3 b$. Size 2 & Eq $4 b$. Size 3 & Eq $5 b$. Size 4 \\
\hline \multirow[t]{2}{*}{ Constant } & $9.863^{* * *}$ & $10.251^{* * *}$ & $10.262^{* * *}$ & $9.675^{* * *}$ & $10.369^{* * *}$ \\
\hline & (47.894) & $(19.292)$ & $(13.909)$ & (22.070) & $(32.359)$ \\
\hline Center City Pop & $0.199^{* * *}$ & 0.127 & 0.159 & $0.279^{* * * *}$ & $0.128^{* * *}$ \\
\hline Density & (5.985) & $(1.380)$ & (1.349) & (4.146) & $(2.668)$ \\
\hline Suburban Pop & $0.101^{* * *}$ & $0.143^{* *}$ & 0.065 & 0.019 & $0.078^{* * *}$ \\
\hline Density & $(5.558)$ & $(2.047)$ & (1.138) & $(0.335)$ & $(3.124)$ \\
\hline Observations & 326 & 58 & 43 & 79 & 149 \\
\hline $\mathrm{R} 2$ & 0.266 & 0.217 & 0.030 & 0.216 & 0.114 \\
\hline
\end{tabular}


Table F - Regressions with dummies for msa size (either $>1 \mathrm{M}$ or $<250 \mathrm{~K}$ )

\begin{tabular}{|c|c|c|c|c|c|c|}
\hline Variables & $\begin{array}{c}E q 1 \\
\text { HC Share }\end{array}$ & $\begin{array}{c}E q 2 \\
\text { HC Share }\end{array}$ & $\begin{array}{c}E q 3 \\
\text { HC Density }\end{array}$ & $\begin{array}{c}E q 4 \\
\text { HC Density }\end{array}$ & $\begin{array}{c}\text { Eq } 5 \\
\text { Pop Density }\end{array}$ & $\begin{array}{c}E q 6 \\
\text { Pop Density }\end{array}$ \\
\hline Constant & $\begin{array}{l}12.708^{* * *} \\
(147.369)\end{array}$ & $\begin{array}{l}12.697^{* * *} \\
(153.875)\end{array}$ & $\begin{array}{l}11.152^{* * *} \\
(177.770)\end{array}$ & $\begin{array}{c}10.181^{* * * *} \\
(80.712)\end{array}$ & $\begin{array}{c}11.036^{* * *} \\
(92.052)\end{array}$ & $\begin{array}{c}10.086^{* * *} \\
(45.677)\end{array}$ \\
\hline MSA HC Share & $\begin{array}{l}0.708^{* * *} \\
(12.823)\end{array}$ & & & & & \\
\hline Center HC Share & & $\begin{array}{l}0.085^{*} \\
(1.928)\end{array}$ & & & & \\
\hline Suburb HC Share & & $\begin{array}{l}0.596^{* * * *} \\
(12.031)\end{array}$ & & & & \\
\hline MSA HC Density & & & $\begin{array}{c}0.182^{* * *} \\
(9.062)\end{array}$ & & & \\
\hline Center HC Share & & & & $\begin{array}{c}0.259^{* * *} \\
(9.725)\end{array}$ & & \\
\hline Suburb HC Share & & & & $\begin{array}{c}0.095^{* * * *} \\
(6.355)\end{array}$ & & \\
\hline MSA Pop Density & & & & & $\begin{array}{c}0.132^{* * *} \\
(5.349)\end{array}$ & \\
\hline Center Pop & & & & & & $0.184^{* * *}$ \\
\hline Density & & & & & & (5.537) \\
\hline Suburb Pop & & & & & & $0.072^{* * *}$ \\
\hline Density & & & & & & $(3.463)$ \\
\hline Big MSA Dummy & $\begin{array}{l}0.115^{* *} \\
(2.447)\end{array}$ & $\begin{array}{c}0.068 \\
(1.467)\end{array}$ & $\begin{array}{c}0.065 \\
(1.208)\end{array}$ & $\begin{array}{c}-0.007 \\
(-0.139)\end{array}$ & $\begin{array}{l}0.145^{* *} \\
(2.524)\end{array}$ & $\begin{array}{l}0.107^{*} \\
(1.932)\end{array}$ \\
\hline Small MSA & $-0.133^{* * *}$ & $-0.093^{* * *}$ & -0.039 & -0.017 & $-0.091^{* *}$ & -0.068 \\
\hline Dummy & $(-3.726)$ & $(-2.629)$ & $(-0.919)$ & $(-0.451)$ & $(-2.013)$ & $(-1.538)$ \\
\hline Observations & 333 & 328 & 333 & 328 & 333 & 328 \\
\hline $\mathrm{R} 2$ & 0.449 & 0.478 & 0.338 & 0.465 & 0.238 & 0.248 \\
\hline
\end{tabular}

***Indicates significance at the 0.01 level; ${ }^{* *}$ at the 0.05 level; ${ }^{*}$ at the 0.10 level. 
Tables and Figures:

Table 1: Descriptive Statistics

\begin{tabular}{lccccc}
\hline & N & Minimum & Maximum & Mean & Std. Dev. \\
\hline Average Income & 331 & 9845 & 52618 & 21104 & 4258 \\
Median Housing Value & 331 & 50310 & 502011 & 121185 & 60907 \\
Metro HC Share & 331 & .11 & .52 & .24 & .075 \\
Metro HC Density & 331 & .36 & 654.17 & 27.37 & 56.81 \\
Metro Population Density & 331 & 2.16 & 3854.40 & 158.55 & 302.10 \\
Center City HC Share & 326 & .04 & .69 & .2447 & .11 \\
Center City HC Density & 326 & 9.10 & 1418.15 & 159.50 & 134.94 \\
Center Population Density & 326 & 51.24 & 7817.14 & 1083.31 & 800.22 \\
Suburb HC Share & 330 & .04 & .66 & .2253 & .08 \\
Suburb HC Density & 330 & .04 & 662.70 & 20.07 & 48.84 \\
Suburb Population Density & 330 & 1.20 & 3943.34 & 110.72 & 261.75 \\
\hline Valid N (listwise) & 325 & & & &
\end{tabular}

Table 2: Correlation Results

\begin{tabular}{lcc}
\hline & Average Income & Median Housing Value \\
\hline Metro HC Share & $.676^{* * * *}$ & $.628^{* * * *}$ \\
Metro HC Density & $.644^{* * * *}$ & $.576^{* * * *}$ \\
Metro Population Density & $.502^{* * * *}$ & $.454^{* * * *}$ \\
Center City HC Share & $.298^{* * *}$ & $.331^{* * *}$ \\
Center City HC Density & $.484^{* * *}$ & $.584^{* * * *}$ \\
Center Population Density & $.304^{* * *}$ & $.416^{* * *}$ \\
Suburb HC Share & $.783^{* * *}$ & $.678^{* * * *}$ \\
Suburb HC Density & $.651^{* * * *}$ & $.567^{* * * *}$ \\
Suburb Population Density & $.506^{* * *}$ & $.456^{* * *}$ \\
\hline
\end{tabular}

*** Indicates significance at the 0.01 level. 
Table 3 - Regional Income and Metro, Center and Suburban Human Capital

\begin{tabular}{|c|c|c|c|c|c|}
\hline \multicolumn{6}{|c|}{ Av Metro Human Capital Share (a-regressions) } \\
\hline Variables & Eq 1a. All regions & Eq 2a. Size 1 & Eq 3a. Size 2 & Eq 4a. Size 3 & Eq 5a. Size 4 \\
\hline \multirow[t]{2}{*}{ Constant } & $10.555^{* * *}$ & $10.880^{* * *}$ & $10.771^{* * *}$ & $10.702^{* * *}$ & $10.270^{* * *}$ \\
\hline & (278.994) & $(135.055)$ & $(89.892)$ & $(108.028)$ & $(197.266)$ \\
\hline \multirow[t]{2}{*}{ Metro HC Share } & $0.415^{* * *}$ & $0.612^{* * *}$ & $0.572^{* * *}$ & $0.500^{* * *}$ & $0.254^{* * *}$ \\
\hline & $(16.625)$ & $(9.941)$ & $(7.122)$ & $(9.263)$ & $(7.799)$ \\
\hline Observations & 331 & 61 & 42 & 79 & 149 \\
\hline $\mathrm{R} 2$ & 0.457 & 0.626 & 0.559 & 0.527 & 0.293 \\
\hline \multicolumn{6}{|c|}{ Center and Suburb Human Capital Share (b-regressions) } \\
\hline Variables & Eq $1 b$. All regions & Eq 2b. Size $1^{a}$ & Eq $3 b$. Size 2 & Eq 4b. Size 3 & Eq 5b. Size $4^{b}$ \\
\hline \multirow[t]{2}{*}{ Constant } & $10.529^{* * *}$ & $10.786^{* * *}$ & $10.637^{* * *}$ & $10.646^{* * *}$ & $10.347^{* * *}$ \\
\hline & $(335.143)$ & (129.969) & $(136.549)$ & $(143.138)$ & $(227.605)$ \\
\hline \multirow[t]{2}{*}{ Center HC Share } & -0.011 & $0.118^{* * *}$ & 0.012 & 0.012 & -0.042 \\
\hline & $(-0.622)$ & $(2.779)$ & $(0.471)$ & $(0.324)$ & $(-1.570)$ \\
\hline Suburb HC & $0.392^{* * *}$ & $0.428^{* * *}$ & $0.443^{* * *}$ & $0.440^{* * *}$ & $0.317^{* * *}$ \\
\hline Share & (20.768) & $(6.953)$ & (10.103) & (11.126) & (10.692) \\
\hline Observations & 326 & 58 & 43 & 79 & 149 \\
\hline $\mathrm{R} 2$ & 0.610 & 0.585 & 0.754 & 0.638 & 0.487 \\
\hline
\end{tabular}

Table 4 - Regional Income and Metro, Center and Suburban Human Capital Density

\begin{tabular}{|c|c|c|c|c|c|}
\hline \multicolumn{6}{|c|}{ Av Metro Human Capital Density (a-regressions) } \\
\hline Variables & Eq 1a. All regions & Eq 2a. Size 1 & Eq 3a. Size 2 & Eq 4a. Size 3 & Eq 5a. Size 4 \\
\hline \multirow[t]{2}{*}{ Constant } & $9.655^{* * *}$ & $9.733^{* * *}$ & $9.695^{* * *}$ & $9.539 * * *$ & $9.670^{* * *}$ \\
\hline & (477.929) & (138.937) & (105.485) & (153.472) & (373.769) \\
\hline \multirow[t]{2}{*}{ Metro HC Density } & $0.109^{* * *}$ & $0.093^{* * *}$ & $0.078^{* *}$ & $0.156^{* * *}$ & $0.103^{* * *}$ \\
\hline & (15.277) & $(5.222)$ & (2.652) & $(6.984)$ & $(6.522)$ \\
\hline Observations & 331 & 61 & 42 & 79 & 149 \\
\hline $\mathrm{R} 2$ & 0.415 & 0.316 & 0.150 & 0.388 & 0.333 \\
\hline \multicolumn{6}{|c|}{ Center and Suburb Human Capital Density (b-regressions) } \\
\hline Variables & Eq $1 b$. All regions & Eq 2b. Size 1 & Eq 3b. Size $2^{a}$ & Eq 4b. Size $3^{b}$ & Eq 5b. Size $4^{b}$ \\
\hline \multirow[t]{2}{*}{ Constant } & $9.424^{* * *}$ & $9.485^{* * *}$ & $9.306^{* * *}$ & $9.324^{* * *}$ & $9.400^{* * *}$ \\
\hline & $(167.071)$ & $(68.394)$ & (42.858) & (72.422) & (120.441) \\
\hline Center HC & $0.078^{* * *}$ & $0.086^{* * *}$ & $0.094^{*}$ & $0.083^{* * *}$ & $0.084^{* * *}$ \\
\hline Density & $(6.230)$ & $(2.731)$ & (2.005) & $(3.024)$ & $(4.966)$ \\
\hline Suburb HC & $0.069^{* * *}$ & 0.037 & $0.062^{* *}$ & $0.106^{* * *}$ & $0.070^{* * *}$ \\
\hline Density & (11.097) & $(1.723)$ & $(2.683)$ & $(6.118)$ & $(8.164)$ \\
\hline Observations & 326 & 58 & 43 & 79 & 149 \\
\hline R2 & 0.464 & 0.328 & 0.330 & 0.441 & 0.423 \\
\hline
\end{tabular}


Table 5 - Housing Values and Metro, Center and Suburban Human Capital Shares

\begin{tabular}{|c|c|c|c|c|c|}
\hline \multicolumn{6}{|c|}{ Av Metro Human Capital Share } \\
\hline Variables & Eq 1a. All regions & Eq 2a. Size 1 & Eq 3a. Size 2 & Eq 4a. Size 3 & Eq 5a. Size 4 \\
\hline \multirow[t]{2}{*}{ Constant } & $12.808^{* * *}$ & $13.510^{* * *}$ & $12.709^{* * *}$ & $13.035^{* * *}$ & $12.283^{* * *}$ \\
\hline & $(154.628)$ & $(59.922)$ & $(45.431)$ & $(71.430)$ & $(121.256)$ \\
\hline \multirow[t]{2}{*}{ Metro HC Share } & $0.801^{* * *}$ & $1.239^{* * *}$ & $0.714^{* * *}$ & $0.963^{* * *}$ & $0.520^{* * *}$ \\
\hline & (14.655) & $(6.351)$ & $(3.807)$ & $(8.003)$ & $(8.202)$ \\
\hline Observations & 331 & 61 & 42 & 79 & 149 \\
\hline R2 & 0.395 & 0.406 & 0.266 & 0.454 & 0.314 \\
\hline \multicolumn{6}{|c|}{ Center and Suburb Human Capital Share } \\
\hline Variables & Eq 1b. All regions & Eq 2b. Size 1 & Eq $3 b$. Size 2 & Eq 4b. Size $3^{a}$ & Eq 5 b. Size 4 \\
\hline \multirow{2}{*}{ Constant } & $12.751^{* * *}$ & $13.412^{* * *}$ & $12.594^{* * *}$ & $12.975^{* * *}$ & $12.376^{* * *}$ \\
\hline & (164.919) & $(51.503)$ & $(54.346)$ & $(70.634)$ & (126.538) \\
\hline \multirow[t]{2}{*}{ Center HC Share } & 0.068 & $0.291^{* *}$ & 0.132 & 0.076 & 0.055 \\
\hline & (1.533) & (2.195) & $(0.987)$ & $(0.846)$ & $(0.963)$ \\
\hline Suburban HC & $0.666^{* * *}$ & $0.878^{* *}$ & $0.486^{* * *}$ & $0.784^{* * *}$ & $0.488^{* * *}$ \\
\hline Share & (14.339) & $(4.546)$ & $(3.720)$ & $(8.041)$ & $(7.632)$ \\
\hline Observations & 326 & 47 & 43 & 79 & 149 \\
\hline $\mathrm{R} 2$ & 0.456 & 0.397 & 0.334 & 0.490 & 0.391 \\
\hline
\end{tabular}

Table 6 - Regional Metro Housing Values and Metro, Center and Suburban Human Capital Density

\begin{tabular}{|c|c|c|c|c|c|}
\hline \multicolumn{6}{|c|}{ Av Metro Human Capital Density } \\
\hline Variables & Eq 1a. All regions & Eq 2a. Size 1 & Eq 3a. Size 2 & Eq 4a. Size 3 & Eq 5a.Size 4 \\
\hline \multirow[t]{2}{*}{ Constant } & $11.092^{* * *}$ & $10.954^{* * *}$ & $11.198^{* * *}$ & $11.030^{* * *}$ & $11.200^{* * *}$ \\
\hline & $(247.576)$ & $(64.342)$ & $(68.444)$ & $(74.956)$ & $(194.098)$ \\
\hline \multirow[t]{2}{*}{ Metro HC Density } & $0.203^{* * *}$ & $0.251^{* * *}$ & $0.154^{* * *}$ & $0.235^{* * *}$ & $0.137^{* * *}$ \\
\hline & $(12.779)$ & $(5.773)$ & $(2.930)$ & $(4.436)$ & $(5.101)$ \\
\hline Observations & 331 & 61 & 42 & 79 & 149 \\
\hline $\mathrm{R} 2$ & 0.332 & 0.361 & 0.177 & 0.204 & 0.150 \\
\hline \multicolumn{6}{|c|}{ Center and Suburb Human Capital Density } \\
\hline Variables & Eq 1b. All regions & $E q 2 b$. Size $1^{a}$ & Eq 3b. Size 2 & Eq $4 b$. Size 3 & Eq 5 b. Size 4 \\
\hline \multirow[t]{2}{*}{ Constant } & $10.166^{* * *}$ & $10.143^{* * *}$ & $10.374^{* * *}$ & $9.720^{* * *}$ & $10.360^{* * *}$ \\
\hline & $(86.541)$ & $(29.578)$ & $(25.941)$ & $(36.598)$ & $(63.195)$ \\
\hline Center City HC & $0.259^{* * *}$ & $0.269^{* * *}$ & $0.216^{* *}$ & $0.355^{* * *}$ & $0.216^{* * *}$ \\
\hline Density & $(9.981)$ & $(3.442)$ & $(2.512)$ & $(6.243)$ & $(6.052)$ \\
\hline Suburban HC & $0.098^{* * *}$ & 0.088 & $0.082^{*}$ & $0.110^{* * *}$ & $0.097^{* * *}$ \\
\hline Density & $(7.561)$ & (1.643) & (1.925) & $(3.075)$ & $(5.355)$ \\
\hline Observations & 326 & 58 & 43 & 79 & 149 \\
\hline $\mathrm{R} 2$ & 0.465 & 0.393 & 0.306 & 0.450 & 0.347 \\
\hline
\end{tabular}




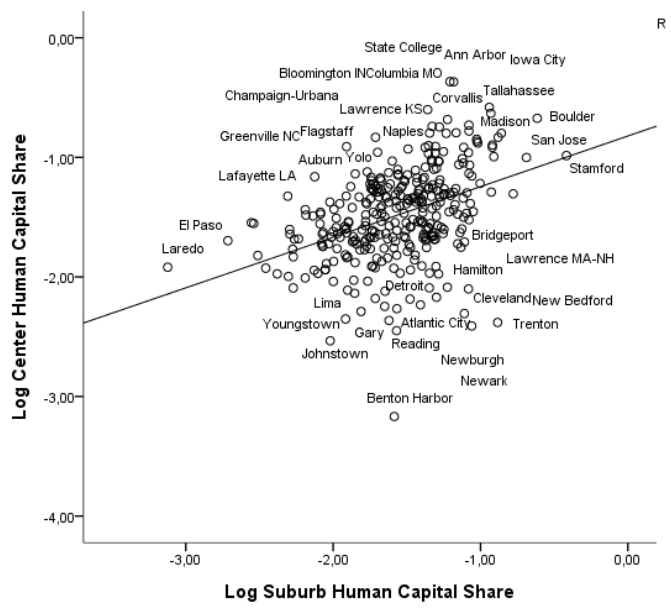

Scatter plot of the relationship between center and suburb human capital shares

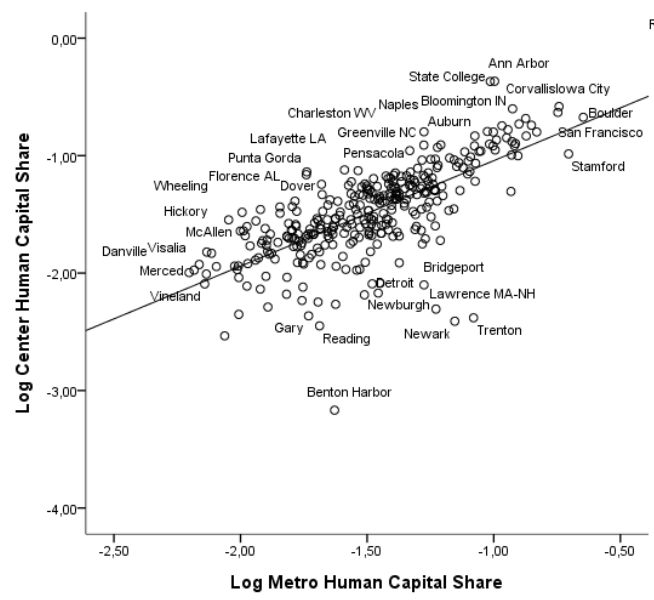

Scatter plot of the relationship between center and metro human capital share

Figure 1: Scatter plots of the relationship between metro, center and suburb human capital levels

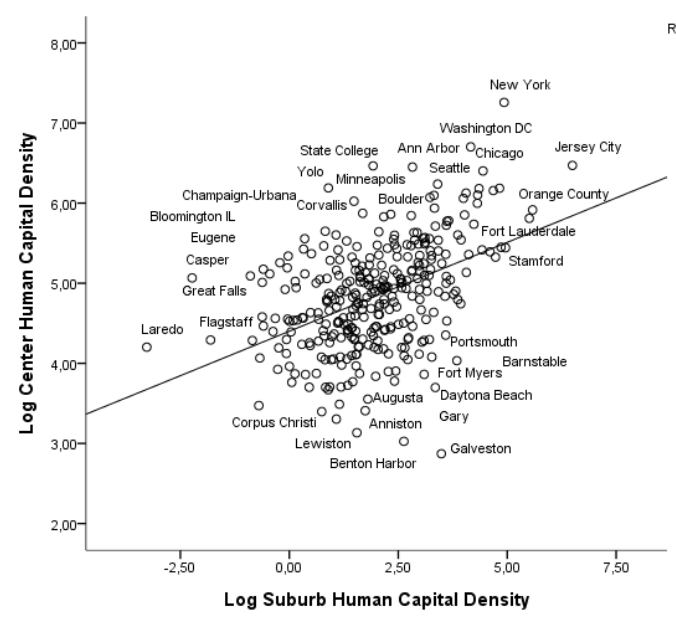

Scatter plot of the relationship between center and suburb human capital density

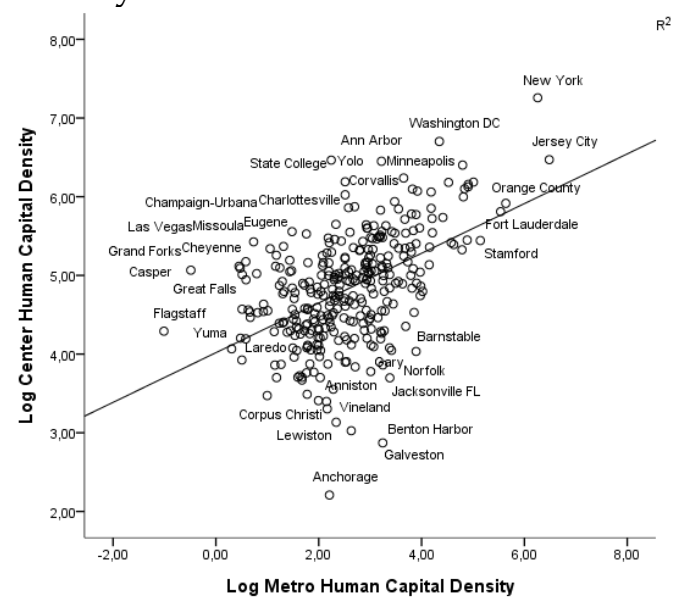

Scatter plot of the relationship between center and metro human capital density 